\title{
TALAVÁN, NOA. Translation as a Science and Translation as an Art. A Practical Approach. Madrid: McGraw Hill Education and UNED, 2017, 173 pp.ISBN:978-8448612573
}

\author{
José Javier Ávila-Cabrera \\ josejaav@ucm.es \\ Universidad Complutense de Madrid
}

The monograph Translation as a Science and Translation as an Art seeks to provide students, practitioners and any other readers interested in the field of translation, with the necessary tools required to embark on the challenging journey of translation. Not only does the book explore the theoretical basis of translation, but also describes these concepts from a practical approach, enriching the pages with tasks and providing possible solutions and commentaries, whose language combinations are English to Spanish, while presenting an analysis on the decisions made during the translation process. From the very first page, Talaván states that the present book does not elucidate any enigmas in the field of translation, but rather offers an array of tools to be considered when dealing with the transfer of different types of texts. This book also illustrates the difficulties that translators face on the grounds of lexical, syntactic, semantic and/or cultural elements. The author emphasizes the dichotomy of translation as a practice in which science and art are two inter-related elements which interact and complement each other. The book, summarised as follows, is divided into five chapters as well as an appendix containing the keys to the exercises proposed in every section.

Chapter 1 lays the groundwork for acquiring general knowledge on the field of translation. The author pinpoints the concepts of science and art and explains their relevance in the context of translation. Written and oral translation are defined and the taxonomy proposed by Jackobson (1959) is presented, which includes intralingual, interlingual and intersemiotic translation. The most relevant contributions in the history of translation are chronologically presented, starting from the Roman period with Cicero's concepts (word-for-word vs. sense-for-sense translation) to Saint Jerome (literal vs. sense-for-sense translation), and from the Middle Agesto the present. The contributions by Holmes and Toury form the crux of Translation Studies (TS) and the importance of Descriptive Translation Studies (DTS) in current research fields is manifested. The contents presented in this chapter serve as an essential historical point of departure in which the basic concepts of translation are explored. 
The basics of linguistic layers in translation are examined in Chapter 2. All the forms of language are examined from the smallest to the largest units in order to help the translator transfer a source text (ST) into a target text (ST). The word as the smallest unit is analysed considering its meaning as propositional, expressive, presupposed and evoked. In cases of nonequivalence at word level, the author proposes a taxonomy of translation strategies (Baker, 2011). In addition, collocations, idioms and fixed expressions are presented as bigger categories. A series of common drawbacks and strategies to be used on these concepts are exemplified and reinforced with some tasks on this matter. As far as grammar is concerned, the relevance of morphology and syntax are set forth, describing the concepts of number, gender, person, tense and aspect, and voice. With the aim of encompassing language in a larger layer, the importance of the text as a linguistic unit is further examined. The relevance of information flow, word order and linear arrangement are justified in order to understand the communicative context. Halliday's (1985) concepts of theme and rheme are therefore explained. The thematic structure is explained by means of the categories of fronted, predicated and identifying theme. Once again, the author proposes a series of strategies to utilize in these cases. Talaván describes the cohesive devices such as reference (anaphora), substitution and ellipsis, conjunctions and lexical cohesion. Last but not least, pragmatics is explained so the reader may understand the use of language in a concrete communicative context. The elements of coherence and implicature are explained and a series of strategies are offered to ease the difficulties which arise from these ideas. This chapter is significant in that it explores varying levels of translation: translation at word, above the word, grammar, text and pragmatics level. These elements are expounded in order to aggregate better theoretical and practical knowledge on linguistic layers.

Chapter 3 seeks to establish a preliminary approach on nonspecialised translation, that is, the translation of humanistic texts. The functional approach of translation is explained by means of the Skopos Theory and Christian Nord's (1997) functional approach, which is presented on the basis of the translation brief/commission, the ST analysis and the translation problems. Beyond the linguistic features tackled so far, the author refers to culture as a crucial element to be considered in translation. When dealing with the translation of cultural referents, the author suggests a taxonomy on categories and scope, pointing out the importance of transferring them in accordance with the field, tenor and mode of the text. Venuti's (2008) concepts of domestication and foreignization are scrutinised and exemplified in order to comprehend the linguistic and cultural features the TT can have. The author states her position to be in favour of middle solutions in this regard, which shows a realistic approach to the professional 
translation practice. The concept of cultural transposition and the possible solutions (including exoticism, cultural borrowing, calque, communicative translation, and cultural transplantation) are here described (Haywood et al., 2009). Amongst all the difficulties translators face, a significant one can be translation loss. Talaván therefore includes a number of types of compensation which can be used in these cases: compensation in kind, place, by merging and splitting. In cases in which more than one decision is to be made, connotative meaning can take place, whose types are attitudinal, associative, affective, reflected, collocative, and allusive. This chapter illustrates a number of concepts which are crucial to better transfer cultural elements, as well as possible solutions which can be regarded.

It is in Chapter 4 where methods, strategies and techniques are scrutinised. Given the variety of scholars who refer to methods, strategies and techniques, Talaván points out the distinction between these three concepts. Newmark's (1988) methods are presented and described including literal, faithful, semantic, communicative translation, and adaptation. Hurtado Albir (2008) distinguishes four methods: interpretativecommunicative, literal, free and philological. Concerning ST oriented techniques, the author describes literal translation, equivalence, borrowing (loan), and calque, foreignisation being the most common ST oriented strategy. As for target oriented strategies, domestication is the most renowned. The author explains the more concrete strategies (some of which include techniques) in this approach: adaptation, compensation, modulation, neutralisation, specification, substitution, and transposition. Footnotes and glossaries are also included as possible translation solutions. A number of strategies (Chiaro, 2010) are also scrutinised when dealing with humour. Puns as humouristic elements are included here and a taxonomy of techniques (Delabatista, 1993) is shown. In addition, translation quality and translation errors are described, as well as the classification by Hurtado Albir (2008) for identifying types of errors. The author emphasises that in order to assess a translation it is important to pay attention to the overall comprehension, the messages transferred, the text organisation, the effect, the register, and the style. The clarification between methods, strategies and techniques make this chapter most valuable inasmuch as readers can elucidate these three concepts which tend to vary in accordance with different scholars, and which can at times overlap each other.

Chapter 5 is devoted to the challenges present in non-specialised translation such as literature. One of the most difficult texts to translate is poetry, given the difficulty in transferring figurative language. In an attempt to do so, different approaches are presented on the basis of Bassnett (2010) and Lefevere (1975): phonemic, literal, metrical, prose, rhymed, blank/free verse translation, and interpretation. As far as the translation of prose is 
concerned, a guide (Belloc, 1931; Bassnett, 2010) for this type of translation is integrated. Drama has also a place in this chapter.Three levels in this type of translation are encompassed following Merino Álvarez (1994): the macro, micro and intersystemic level. In addition, the challenges which can appear are included and adapted from Hurtado Albir (2008). Another linguistic challenge worthy of mention is dialect. Among the possible strategies (Sánchez, 2009) that can be used are parallel dialect translation, dialect explanation and standardisation. Regarding techniques, the author mentions dialect compilation, pseudo-dialect translation and dialect localisation (Perteghella, 2002). In the final section of the chapter, the author explores the art of translation, aiming to transmit to the reader that just as it is possible to learn science, one can also learn the artistic skills embedded within the discipline. Her idea may, however, appear in opposition to the general belief that certain gifts for talents cannot be learnt. All in all, the type of translation operations reviewed here include a source of tools which can be utilized in order to unravel the linguistic subtleties which make the translation practice a challenge in these types of texts.

This monograph is a must for any reader who wants to gain insights into the essential theoretical and practical concepts on translation. Talaván's view on translation as a science and as an art supports the importance of both disciplines and states that translation is possible, despite the many difficulties. The book maintains an academic register and several of the numerous examples and discussions that are illustrated are borrowed from authentic materials (including classic literature, audiovisual materials, specialised articles and the like). The potential of the combination of theory and practice in the book can give the reader a better understanding of the translation theory which materialises in the TT through translation operations, which clearly shows the nature of this practice. Apart from covering the most important theoretical concepts within the discipline of translation, this book provides a number of tasks and their possible solutions, along with detailed analyses and examples, all of which make it a distinguishing work which positively contributes to the literature on translation. 